\title{
Social Interaction in the Art of Acting: Forms and Phases
}

\author{
Charlotte L. Doyle \\ Sarah Lawrence College, USA \\ E-mail address: cdoyle@slc.edu
}

ARTICLE INFO

\section{Keywords:}

Creative process

Stage acting

Social interaction

Multiple realities

\section{Article history:}

Received: 15 March 2016

Received in revised form: 29 June 2016

Accepted: 7 September 2016

ISSN: 2354-0036

DOI: 10.1515/ctra-2016-0014
A B S T R A C T

Creativity is here construed as an activity taking place in phases over time, one everywhere imbued with the social, whether the creator does much of the work alone as in fiction writing or with others where the creation itself is collaborative such as jazz improvisation. This paper considers the creation of theatrical roles, a domain in which some phases of the activity take place under solitary conditions and others involve face-to-face interaction. Grounded in a research review, the paper examines the phases of the creative process in scripted acting. It notes the kinds of social relationships in each, the roles of intention, reflection and spontaneity, the forms of interaction in terms of Schütz's multiple realities and the ways in which those realities interact.

Psychologists are increasingly looking at creativity as an activity, something people do rather than what they are (Glăveanu, Lubart, Bonnardel, deBlasi, et al. 2013). A useful focus is the creative episode, the process from the first inkling of a creative project to its completion-an activity which unfolds over time (Arnheim, 1962, Doyle, 2011). And, increasingly, the indispensable role of the social has been recognized. Csikszentmihalyi (1997) pointed out that the creative activity involves socially learned internalization of a domain and field. Amabile (1996) documented the role of others in fostering internal or inhibiting intrinsic motivation for creating. Glăveanu (2010) added that creative work involves interaction with culturally created mental tools and material objects and that the creator's identity includes belonging to a creative community.

A novelist once told the author, "Writing fiction is something you do in a room alone." Yet his creative activity was imbued with the social. The very language in which he wrote was culturally learned. He used cultural objects, paper and pen, with which to write. His education and interest included immersing himself in British and American literary traditions (learning his domain). He knew other writers (a writing community) and understood what he needed to do to get his work in print (the publishing field). The seed for his 
prize winning novel was an incident he read in a newspaper (a cultural object) about an event in a library (a cultural institution). The novel drew on the voices and personalities he remembered from childhood. When he finished a draft, he gave his manuscript to an editor who made comments that led to important revisions. Still, there was no question that the writer was the creator of his novel. No one else could have written it as he did.

Some creative projects have no single creator. In a few domains, a collaborative creative process is the created product; it emerges from one-time improvisation in the present. Two examples are jazz performance (Berliner, 1997) and improvisational comedy (Sawyer, 1997). Here the creation itself is constituted by spontaneous face-to-face interaction of the performers. Each improviser comes to the performance having individually internalized the skills and history of the domain, having navigated opportunities and obstacles created by their field, reacted to encouragement and criticism in the past, and developed an identity that included belonging to a community of improvisers. Though improvisation depends on the individual social history of each participant and each makes a unique contribution, the creation emerges only when the improvisers come together, a process Sawyer (2010) called "collaborative emergence."

This paper reviews research on how actors describe their activities as they create and perform scripted roles for the stage. Actors are often honoured for their performances as individuals; yet their performances depend on an ensemble in interaction creating in the present. Furthermore, as the creative episode in acting unfolds in phases over time, some phases consist of activities which take place when an actor is "in a room alone" whereas others involve interaction in the present.

\section{Phases}

Once contemporary professional actors are cast in their roles, they do independent work on their scripts prior to and in between rehearsals. They bring the results of this solitary work to the second phases, rehearsals in which they are face-to-face with the other actors, the director, and various other members of the production team. The third phases, often solitary, take place on performance days when actors are in their dressing rooms preparing to go on stage. The fourth phases are performances when the actors are faceto-face with both the other actors and the audience. This paper will review research on creating and performing roles as the phases unfold.

\section{Sources for the Review}

Nemiro (1997), to explore the creative process in acting, asked a series of predetermined questions as she conducted interviews with three actors who varied in theatre experience; her results listed role creation techniques, features of the social context that actors saw as facilitating or inhibiting creativity, and themes related to the experience of perfor- 
mance. Bandelj (2003), to develop a sociological understanding of role creation, interviewed advanced acting students and thematized interviews from Film Commentary. Noice \& Noice $(1997,2002,2006)$, investigating the cognitive processes involved in acting, did a whole series of studies which included asking professional actors to think aloud as they studied scenes and interviewing actors about the process. Konijn (2000) studied performance by sending questionnaires to professional actors with respect to their performances in a scene late in the run of their plays. The questionnaire asked the actors to compare the intensity of the emotions conveyed to the audience with those they experienced. The author conducted four narrative, phenomenological interviews with professional actors who appeared in featured roles on Broadway and off-Broadway in New York. Findings were reported in two previous papers (Doyle, 2013; 2016). Some unpublished material from those interviews will also be included in the review.

\section{Acting Traditions: The Prehistory of the Creative Episode}

The approach to theatrical acting has varied through history and in different cultures. Today, the first step in becoming an acting professional typically involves formal study, and different contemporary institutions provide different guidelines for how to create a role. One major difference has been termed by actors themselves as working "outside-in" or "inside-out" (Fox, 2006). The training of European actors is chiefly "outside-in;" a tradition which can be traced back to Diderot (1957); it teaches students to base their characterizations on skillfully imitating what they have seen in others. Many American schools base their training on the work of the Russian director, Stanislovsky (1986) and ask actors to use their own experiences in one of two ways: in his early work, by drawing on emotion-laden memories (Strasberg \& Morphos, 1987) and, in his later work, by placing themselves in their characters' circumstances (Moore, 1984).

The subjects in the studies by Nemiro (1997), Bandelj (2003) and Noice \& Noice (1997) were American actors who were schooled in Stanislovsky methods. In her study of performance, Konijn (2000) sent questionnaires to Dutch and American actors. Two of the subjects in the author's studies were trained in the American tradition; two in the British. As we shall see, training - whether in the European or American tradition - determined, in part, how actors prepared their roles especially in how they carried out the independent work.

\section{Forms of Sociality: the Work of Alfred Schütz}

This paper proposes that Schütz's work is key to understanding the kinds of social interactions involved in the various phases of the creative process in acting. He himself considered a related question; in an article entitled "Making music together: A study in social relationships," Schütz (1951) pointed out that a musician alone in a room practicing 
a piece of music brings to it a socially learned stock of knowledge. He also put forward the idea that the musician is in a contemporary relationship, an intersubjective relationship with the composer, as the musician experiences and articulates the composer's musical thought. This is no ordinary relationship; the musician need not know what the composer looked like, the details of personal life, or even the composer's name. The ground of the relationship between musician and composer is the shared world of music. In performance, the musician is in a face-to-face relationship both with the fellow players and the audience.

Doyle (2016) concluded that the life worlds of actors can be illuminated by one of Schütz's best known contributions, the phenomenological concept of multiple realities. It is relevant to exploring the social interactions of actors as well. Schütz (1945) distinguished among different experiential worlds which he called different provinces of meaning. He contrasted the everyday world of daily life with worlds in which the everyday world is bracketed and people temporarily give the accent of reality to other provinces of meaning. He gave as examples:

... the leap into the world of dreams... the radical change in our attitude if, before a painting, we permit our visual field to be limited by what is within the frame as the passage into the pictorial world... the child's turning toward his toy as the transition into the play-world... the decision of the scientist to replace all passionate participation in the affairs of "this world" by a disinterested contemplative attitude. (p. 553)

He added that shifts from one province to another are common within a single day, moving from the everyday world of action, to daydreaming, to thinking, to contemplating a painting.

Each reality, Schütz wrote, can be characterized by a cognitive style; provinces vary from one another in specific features-among them sense of self, experience of time, dominant mode of action, epoché (what is taken for granted) and the kind of sociality. The reality of the everyday world of objects and persons is taken for granted (unlike the philosophers who, in a theoretical world, begin with doubt). The dominant mode of action in the everyday world is working, acting on the environment in order to achieve goals of personal relevance. A common form of everyday sociality is face-to-face. Here the interactors share time and space and are aware of each other as human beings who are centres of action, feeling and thought. They each have a developed identity that connects them to their personal pasts, their goals and their hopes for the future, though in the moment they are living in and through their acts. 
The scientist sitting alone is in a theoretical world; the everyday world is bracketed; the reality now being experienced is the domain of science: It consists of what has been done by scientists in the past on a problem and a possible future which brings its solution, one which will be shared with contemporaries. The dominant activity is reflection. At times, scientists reflect together as they discuss a scientific problem, a socially shared theoretical world. Fantasy worlds are another example of provinces in which everyday reality is bracketed-daydreaming and children's play are examples. In the case of children's play, the fantasy world is often co-constructed and shared.

\section{Phases in the Light of Schütz's Multiple Realities}

The research surveyed here is organized by phases and queried in terms of the forms of social interaction in various activities as actors create and perform their roles.

\section{Independent Work on the Script}

Typically, there is a lag of weeks between the time an actor is cast in a role and the first rehearsal. Actors use the time to work on the script independently.

Reading the play: The obvious first step all the actors reported was reading the script (Noice \& Noice, 1997) and, as readers, having an emotional reaction to it (Doyle, 2016). Here they were in an intersubjective relation to the playwright, sharing the experience of the story the playwright created - a story world (Oatley, 2002). The story world is a social one, full of characters in interaction with one another. They interact in ways that, depending on the style of the play, more or less reflect possible events in the everyday world. Though in reading the actors were transported into a story world, this was not a world in which the actor actively participated; the social scenes unfolded as the actor sat and read.

Actors reread the script multiple times, and gradually their focus became centred on the characters they were going to portray.

A theoretical world: Analyzing the play. Noice \& Noice (1997) and Nemiro (1997), noted that their actors analyzed their scripts systematically, breaking the text down in terms of a hierarchy of objectives. At the lowest level, they broke down each individual scene examining each change in intention or emotion (one beat). For example, one Noice \& Noice (1997) actor broke down his scene into these beats: talk her into letting him in, make friends, make her an ally, continue the relationship. The next level objective was for the whole scene: "Talk Cory into letting him use her apartment." His character's overall play objective was "to maintain current lifestyle." And the character's life objective was: "to have a ball." (p. 17). Many, but not all of the Bandelji (2003) did this as well. One of the author's actors broke down the script this way; two others analyzed each scene and the relation to the whole, but not as systematically (Doyle, 2016). All these actors typically 
entered theoretical worlds; their relations to their characters were somewhat like the relation of a psychologist using theory to understand a patient. Not only did they ask themselves, why did my character say that? What is he trying to do here? They also asked, what is the personality? What forces shaped him? What is the character's emotional journey through the play? For example, one of the author's actors saw his character as an orphan who gained control of a chaotic world by establishing rules and adhering to them rigidly. It should be noted that another of the author's actors, did not reflect on the play explicitly. Instead she read the play repeatedly, entering the play's world over and over again. As she read, realizations came to her (Doyle, 2016). She was more like someone observing a person's interactions over time and getting to know the person implicitly through those observations.

Through analysis or realization, the characters the actors were to play became for them complex human beings with distinct ways of being in the social world of the play.

Learning the cultural world of the character. Plays often take place at a time and in a place other than the one the actors live in. Bandelj (2003) noted that her actors often studied contemporary cultural resources such as books, films and internet information to gain insight into the social structures and physical environments in which their characters lived. For example, she noted that Harvey Keitel, as part of his preparation for playing a role in The Duelists read books, screened films and consulted experts to get a feel for the culture in which his character lived. Like anthropologists, many actors, in a theoretical world, seek to understand how culture shaped their characters.

Learning lines. Part of the profession of being a professional actor in scripted plays is remembering the lines. Noice \& Noice (1997) reported that once their actors thoroughly analyzed the play, they magically knew their lines. One of the author's actors reported this as well, but others set about this professional demand memorizing by rote. This meant interacting with the script, but it tended to be a solitary, everyday world activity. They spoke of not wanting to freeze line interpretations prior to rehearsal, instead wanting them to emerge as they interacted with the other characters in the world of the play (Doyle, 2013). So their task was working in the everyday world to achieve a goal. Though they were working on the playwright's script and speaking the playwright's words, they were trying to avoid entering the playwright's world.

The pictorial world: Visualizing the character. British acting training includes picturing the appearance of the character. For the author's British-trained actors, this meant using a cultural resource, the internet, to find appropriate images. Once they found the image, they tried to get to know the person being pictured by entering what Schütz called a picto- 
rial world. One of the author's British-trained actors elaborated on what he did with a photo he brought to show the interviewer:

I am not just looking at a physical image, but l'm trying to get inside of it. And usually...you can sort of read the entire human being... what they're thinking at the moment...how they move, why did they chose those clothes they're wearing. How are they standing, where's the tension? Where's the relaxation... How, if that person was to move and walk and talk, how would they emerge from that picture into the world?

Getting to know a person from an image through contemplation and imagination was part of the work for this actor.

Memory worlds: Enacting the social past. Both Nemiro's (1997) and Bandelj's (2003) studies of American actors reported that their actors found aspects of their characters in the Stanislovky way by transferring emotional experiences from their own lives to their characters. One of the author's American actors gave a very specific description. His character was a father with passionate, loving concern for the well-being of his daughter. To awaken in himself the emotions involved for a scene in which he expressed those concerns, he went back to the time when he first held his new-born son. As he held the baby, he looked down and said, "I am going to take care of you." The baby immediately stopped crying. The father did not simply remember this past event. He put himself in a memory world, becoming again the young father he once was, cradling his arms, looking down, and speaking those words aloud (Doyle, 2016). The past interaction with his baby became a vivid social event that engaged his body in the present.

The author's British-trained actors used their pasts to bring their characters into their bodies in another way. They identified memories of someone who resembled their characters and, as Diderot suggested, imitated with their bodies what they saw. For example, one enacted his father's angry pointing (Doyle, 2016).

These re-enactments of social experiences move the actors from learning about their characters to experiencing in their bodies, the feelings, attitudes and approach to the social world of their characters as past social events become present.

Summary of Phase 1. The actors' independent work involved a contemporary relation with the playwright in a shared story world when first reading the script. They developed various kinds of relationships with their characters and became increasingly acquainted with them, entering several different provinces of meaning to do this. Using their stock of social knowledge, they entered a theoretical world, reflecting line by line and scene by scene on their character's objectives, tracing emotional journeys, and grasping their 
personalities as a psychologist might. Using cultural resources, they studied the historical and social milieu of the play. Some entered pictorial worlds, in which they sought to become acquainted with a pictured person. Some re-enacted past social events in the present either by drawing on their own feelings and actions or imitating those of others. The work in the room alone, whether based on European or American-style training, engaged the social in several different ways as they worked on their roles.

\section{Rehearsals}

Actors bring the results of their independent work to rehearsal. But actors reported that their ideas about their characters and how they portrayed them changed radically through the rehearsal process (Doyle, 2013). The rehearsals brought three kinds of sociality, each with a different form of interaction: face-to-face interaction in the everyday world; shared analysis of the play's scenes, characters and culture in a theoretical world; and face-toface interaction as characters in the drama world, the interaction of actors as their characters in the world of the play.

An everyday social world. From the first rehearsal, actors met their fellow actors, the director and other members of the production team in casual face-to-face conversation before the work began and during breaks. Nemiro (1997) reported that directors enhance or inhibit creativity in terms of features of their relationships. Did the actors trust the director? Did they feel respected? The author's actors spoke of interpersonal relations among the actors, especially expressing appreciation for the ways their fellow actors supported them (Doyle, 2016).

A shared theoretical world. Director and actors reflect on the play together, drawing on their literary, psychological and cultural knowledge, and as drama critics. They discuss the meaning of scenes, the motivation of characters, "what worked and what didn't" in scenes just enacted, and the intended effect on the audience. Actor and director sometimes disagreed; since directors were in authority, actors often accepted interpretations or integrated them with their own in some way (Doyle, 2016). For example, one of the author's actors and her director had different ideas about to whom a given speech was directed. She thought it was addressed to her character's son; the director saw it as speaking to herself. Asked about how this was resolved, she said, "We just kept working on it and it kept getting more specific...it is certainly both things."

Entering the drama world. The actors, as they worked on scenes, often at first intentionally enacted ideas that they brought to rehearsals. But because they were now in interaction with other actors, they were confronted with responses that they needed to react to. Gradually, the sense of enacting intentions dropped away, and from time to time, they ex- 
perienced "becoming" their characters in the drama world. Thus the actors interacted in that world from the perspective of their own characters. Noice \& Noice (2002), who called this "active experiencing," described it this way:

If the situation calls for character $A$ to plead with character $B$, therefore actor A pleads with actor B...the actor playing character A does not try to look and sound like someone pleading; he or she simply pleads "for real" with the other actor. As a consequence of this real doing, active experiencing cannot be purely cognitive, but necessarily involves the type of cognitive-emotive-motor processing that would be inherent in any human interaction. (p. 10)

This "real doing, in Schützian terms, involves bracketing everyday hopes, fears and objectives. The human interaction, though resembling everyday motivated actions, is in the drama world. The actors are working, having effects on the environment, but the goals they work for are those of the characters, not their own.

Being in the character's world meant paying close attention to what other actors-astheir-characters were saying and doing. One of the author's actors told of listening as an important step in his professional development

When I started out acting, it was always guys talking and you're thinking,

'My line is... Now it's just, listen. Just listen, and it makes you very, very vulnerable and it makes you very free.

Being in the character's world meant reacting spontaneously (Nemiro, 1997); her actors described it as "keeping oneself open, living in the moment, becoming an instrument for the work, and allowing one's instincts to take over." (p. 235). As a result, actors are sometimes surprised by what they found themselves doing pre-reflectively. One of Bandelj's (2003) actors described it this way:

Once you do give a character a life and you are up there playing this person, those things just come to you... if I had sat there for three hours trying to think of something, that never would have come to me.... A lot of it is natural because you breathe as this person, and then it just comes (p. 405).

One of the author's actors gave this example: "In rehearsal...walking in a tight circle, (which) as a rational idea never would have come to me, just started happening" (Doyle, 2016).

One intriguing aspect of how some actors described being in the character's world was that they spoke of it being "to some extent" and "greater or lesser" (Doyle, 2016). There were two ways the drama world was "greater or lesser." One was the relative vividness and differentiation in the experience of the character's world. The other was that in rehearsal the drama world was intermittently interrupted and the actor was thrown back 
into the theoretical world or the everyday world. One of the author's actors spoke of forgetting a well-memorized line, saying, "Then you have to figure out what you don't know." Nemiro (1997) noted another cause for being thrown out of the drama world--when fellow actors stopped listening.

\section{The Various Rehearsal Worlds and Their Interaction}

Each province of meaning engaged the social in a different way. The self of the everyday world who socialized with cast and director was the historical self, the self striving to be a respected member of the acting community and for recognition from the wider social world. In the shared theoretical world, the ground of interaction was the play and the dominant activities were reflecting and analyzing together. In the drama world, where, more and more as rehearsals proceeded, the sense of self was as the character, the lines and actions were taken for granted and the social interaction was spontaneous with each actor-as-character responding to the others.

At the same time, sociality in one province of meaning affected the others. When actors trusted and supported one another, the drama world became deeper. The relationship with the director affected this as well. Mutual respect allowed actors to take risks and to lose themselves in the drama world more fully. The theoretical discussions, if they went against an actor's ideas, sometimes felt like criticisms and affected both everyday relationships and the degree of immersion in the drama world. Everyday intentions such as, I am going to listen more closely, affected interactions in the drama world in a pre-reflective way. And each time one actor acted on the intention to do something new, the other actors -as-characters in the drama world found themselves responding in a new way as well.

As rehearsals proceeded, the social interaction in the drama world became increasingly vivid, free and spontaneous, and at times surprising. Later, in reflecting on what they did pre-reflectively in the drama world, actors came to new insights into their characters.

\section{Phase 3: Preparing to Go on Stage}

Dealing with everyday feelings. When the actors first came into their dressing rooms, the coming event, performing before an audience, dominated their everyday worlds; it meant being judged by others on a trait crucial to their everyday identities, the ability to act. Actors reported feelings from mild apprehension to anxiety. These feelings became magnified by the anticipation of the presence of a peer, an agent, or a critic (Nemiro, 1997). In response, actors intentionally carried out activities to focus attention away from appearing before an audience and onto their bodies; the author's actors undertook activities such as physical exercises, re-enacting moments of peace, meditation; one even practiced balancing on a board atop an exercise ball and juggling. 
Becoming the character. Putting on makeup and getting into costume began as an everyday activity, but the author's actors described it as transforming. One of them said:

Putting on the make-up was just perfect because I would literally just transform... l'm putting all the stuff on my eyes...painting on this character... and then I would just sit there... and look until he came and was looking back at me. (Doyle, 2016).

Nemiro (1997) noted that her actors spoke of enacting the prior circumstances of their characters before the first stage scene and one of the author's actors did that as well. Another had a different way of getting into his character's world before going on stage. A particular line, spoken in the accent of his character, always brought him into the character's world.

\section{Phase 4: The Social Worlds of the Stage}

The transition from the everyday to drama world. Making their way from their dressing rooms to the wings of the stage, actors are back in the everyday world. One of the author's actors described the experience of her first entrance in her play

...the lights are going to go out ...l'm going to have to get in, in the dark -

here's a piece of glow tape, here's a piece of glow tape - I'm going to sit...

here I am in this chair, my chair. This night. Awake. Moonlight...Listening...

l'm looking out the window...

There was no window; she was looking out into the audience and listening to the conversation between her son and her daughter-in-law in another part of the stage (Doyle, 2016).

Actors also spoke of an in-between step, acknowledging the everyday reality of appearing before the audience. Explicitly acknowledging this was essential in order to move into the character's world of feeling and doing. One of the author's actors said:

You are an actor...there's an audience out there. And other actors on the stage...You don't keep your awareness. It's just something you have when you go out there.

In and out of the drama world. As in rehearsal, actors spoke of living in the world of the play when performing on stage. They also had words for various experiences when they were not in the character's world. One was being in the everyday world intentionally trying to convey the character's feelings; this is often described as "indicating" (Noice \& Noice, 2006). That is the experience Konijn (2000) suggested was typical. She saw the actor as being in the everyday world with everyday concerns such as competence and self-image; she wrote of actors impersonating their characters' emotions. As the author's actors described their experiences on the stage over time, they spoke of moments when the awareness of self as an actor before an audience concerned with competence and self- 
image became the centre of experience. One spoke of a critical inner voice that at times made harsh judgments on his acting when he indicated rather than allowing the character to react. At these times, he said, he felt as if he was "lying to the audience."

The other opposite to the drama world involved mechanically doing what is required without inner feeling or explicit effort which actors described as "mechanical," "technical" or "phoning in." Konijn (2000) theorized that actors intentionally reeled off well-rehearsed inner representations of their characters without feeling the character's emotions. She found support in questionnaires querying actors about felt emotion in a scene late in a run. The author's actors told of times when an inner blueprint was simply enacted without inhabiting the drama world. For example, one said, "Sometimes into performance you get stale. You get into habits with other actors and you get lazy." This was especially likely to happen during a long run, perhaps accounting for Konijn's results, since she queried actors about their experiences in a scene late in their runs. On the other hand, Nemiro (1997) reported that her actors sought ways to sustain and improve their performances, to continue to discover as their characters. Two examples of such activities reported by the author's actors were rereading the play to come up with new insights and intentions and resolving to listen more closely to the others as their characters on stage.

Relationships with the audience. One theme that emerged in Nemiro's (1997) study was interacting with the audience, of actors "tailoring their performance to the energy level of the audience" (p. 234). She gave the example of one actor sensing the audience's generosity and so feeling free to get a little wild. The author's actors spoke of feeling the audience presence even when they were in their character's world. One said that she was not particularly aware of the audience and yet spoke of the audience as "the fuel of the evening." Asked whether her awareness shifted from her character's world to the audience, she said, "It's simultaneous." Another noted he could be $100 \%$ in the character's world; still, he said, "I can sense the audience being more involved, leaning forward. I'm seeing them laughing or crying." When he was asked to clarify, he suggested an analogy to driving: you may not be explicitly aware of the road and your mind can be elsewhere, but without thinking you are responding to it with small adjustments and if something requires it, you can tune into it immediately." Another of the author's actors had a different analogy:

It's like being in a reoccurring dream... Even though you feel like you're totally in it, you're not alone... When they (the audience) are all there with you in that dream, it's priceless (Doyle, 2016).

These statements indicated that for the actor, even when interacting as their characters immersed in the drama world, the audience is on the horizon of experience. To the extent 
that the audience has also been transported into the drama world, the sense of a shared experience heightens the drama world for the actor.

Intrusions of the everyday world. Actors also told of being thrown out of their character's world by forgotten lines, audience restlessness, cell phones going off, candy wrappers rattling, and the like. One of the author's actors spoke of needing to acknowledge again, that he was an actor before an audience and then getting back "in it." Asked to describe a specific example of getting back in, he said, "wanting a drink;" he was now back in the drama world experiencing the feelings and intentions of his character.

The most dramatic everyday world intrusion is stage fright, something experienced at one time or another by even some eminent and highly experienced actors (See, for example, Olivier, 1986). Though this was a very rare experience for one of the author's actors, he gave a graphic description:

It's just panic...Heartbeats, dry mouth...you're completely disoriented. And people are looking at you...You forget your lines, you forget the script. You don't know what play you're in and people are looking at you...It's humiliating...

The everyday social world and his body now dominated.

Spontaneity in the drama world on stage. Just as in rehearsal, a feature of living in the drama world on stage was pre-reflective. One of the author's actors said, "The words come out of you in ways you've never said them before and they are right." Actors, faceto face, attend closely to one another and respond as their characters in the moment, spontaneously (Nemiro, 1997). As in rehearsal, when a fellow actor did something new, that led to a new response (Noice \& Noice, 1997; Doyle, 2016).

Accidents on stage required spontaneity as the character. One of the author's actors told of a gun that was supposed to go off but failed to fire. At first that put him back in the everyday social world thinking about the audience, "The audience paid to see it...Why didn't they fix it?" But then he got flustered as his character: "You are in the forest and there's a bear there and the gun doesn't go off. That's bad, man. That bear can attack you" (Doyle, 2016).

Actors also spoke of the relation between pre-reflective spontaneity on stage and all the prior work that went into creating their character's world. One of the author's actors said:

It's like being in the moment any time except that in this case, you've been rehearsing a play, your attention and focus is all on it. And you're doing something with other people... So it's informed... by all these techniques and concentrations and experiences - repetitions to make this thing happen... But the experience is one of presence. And maybe that's why when acting is working well, it maybe because l've found a way of being in the 
moment that is even more heightened in some ways than if it's just myself having a thought or watching a sunset...But it's spontaneous. It's not a contradiction (Doyle, 2013, p. 57).

Phase 4: Summary. Experiences in the drama world on stage have many of the features of the everyday social world: face-to-face interaction, shared time and space, and working to fulfill goals, spontaneous, pre-reflective responding. The words, the movements and the events of the play are taken for granted and provide the structure within which that spontaneity takes place. The self is that of the character with the character's motivations, not those of the everyday self, giving shape to attention, intention, feeling and action. Yet the everyday world before the audience and the concerns and intentions of the everyday self are latent or present horizons that, occasionally, or, for some actors more frequently, become the centre of experience.

\section{Discussion}

We have seen the many different kinds of social relations as actors prepare and perform their roles. Even before rehearsals began, actors developed an intersubjective relationship with the playwright as the actor experienced the social world created by the playwright's words. The actors developed relationships with their characters as the actors reflected on the character's goals, objectives and emotional journey through the play. They re-lived relationships with people and events from the past to experience the character's body. The rehearsal hall brought three kinds of sociality, that of the everyday world, a shared theoretical world as director and actors reflect on the play together, and the drama world as the actors interact as their characters. Arriving at the theatre on performance day, they were dominated by the looming future of appearing before an audience (everyday world) and the task of transforming into their characters (a step into the drama world). Performance brought face-to face interaction with the audience - either as actor in the everyday world or immersed in the drama world, yet aware of the degree of audience shared involvement.

As Doyle (2016) pointed out, one of the features of the process of creating a character is the interaction between intention and the non-reflective, allowing events to unfold without intentionally controlling them. Throughout the creation of the character, the actors intentionally entered worlds which they then no longer intentionally controlled. They intentionally entered the playwright's story world in reading and allowed the words to create experience. They decided to enter the pictorial world and let the image guide them. They prepared to enter the drama world, sometimes with explicit intentions, but then reacted to the interaction as it was unfolding. 
Another feature is that the worlds interact in at least two ways (Doyle, 2016). The various worlds actors visit, leave a residue that affects subsequent experience. After reading the play and experiencing the playwright's story world, the actor knows the story in the everyday world. Whether experiences with other actors and the director are positive or negative in the everyday world affects the degree of immersion in the drama world. All the preparations - in the theoretical world, the memory worlds, the pictorial world - prereflectively become integrated as the character interacts with others in the drama world. The preparations in the dressing room just prior to performance prime the entrance into the character's drama world on stage.

In addition, when one social world is in the centre of experience, another may be on the horizon. The clearest example is in performance when actors were fully in the drama world but dimly or implicitly aware of the audience (Doyle, 2016). Just as the experience of a figure is affected by the background in perception, the vividness of the actors' drama world experience was affected by the degree of audience immersion in the background, and, as in the perceptual figure-ground relationship, there could be figure-ground reversals. The drama world may recede into the background and the everyday relation to the audience may become the centre of experience.

What of the inner blueprint, the internal representation of the character's emotional journey? Konijn (2000) suggested that spontaneity in performance was an illusion because actors were enacting internal representations. Yet actors spoke of spontaneity and unexpected discoveries as essential features of both rehearsal and performance. However, spontaneity and internal representations need not be seen as opposites. Rather than providing mechanical, rigid templates, internal representations are often patterns which are flexibly adapted and modified to the present situation (Piaget, 1952; Hassan, Bargh, \& Zimerman, 2009). For example, Bruner (1973) pointed out that babies develop schemes that enable them to reach for an object with accuracy; the schemes, separate, rigid two- part movements at first, come to be integrated and flexibly adapted to the shape and distance of the object, features that may be different with every reach. Flexible non-reflective adaptations of inner representations to present social interaction reoccurred during rehearsal and performance; the integrations emerged spontaneously when actors "lived" in the world of the play as their characters and responded to one another.

One of the author's American actors suggested another important source of spontaneity. She no longer relied on her training which called for re-enacting earlier emotional experiences à la Stanislavsky. Instead, she realized that her past experiences, her emotions, her ways of reacting in the everyday world were "all part of the flowing river" when 
she was "present" in the drama world. Her everyday experiences and ways of being became part of the complex integration which allowed her character to interact spontaneously with other characters in rehearsal and on stage (Doyle, 2016). It is likely that this "flowing river" is a pre-reflective aspect of role creation for other actors as well.

Having created a role itself became part of "the flowing river." The author's actors told of how the experience of having portrayed a character affected their everyday social understanding. They spoke of realizing new human possibilities in themselves and others.

\section{Final Comment}

The creation of a character for a scripted play is both an individual and a collaborative accomplishment. The cultural institutions that bestow awards and bring fame to actors tend to focus on acting as an individual achievement; the study of role creation suggests that more recognition should come to the ensemble. The interviews revealed that featured professional actors work very hard to create their characters. They have learned to enter different provinces of meaning, each with its own form of sociality in their independent work. They enter into shared theoretical worlds with one another and the director. But interacting as their characters in the drama world was central; it both drew on, and radically modified, prior work. It was here, as they listened and reacted to others as their characters, that they made unexpected discoveries, here, where all the prior work and the personal experiences that formed them spontaneously came together.

Social interaction in the drama world was an experience out of the everyday. It was the essential condition that allowed actors to experience a way of being human, different from their everyday experiences. At the same time, the drama world interaction both expressed who the actors were in everyday life and contributed to who they were coming to be.

This paper has presented ways in which Schütz's work illuminates the forms of social interaction in different phases of the creative process in acting. This kind of analysis may be helpful in understanding the role of the social in other domains of creative activity.

\section{REFERENCES}

Amabile, T. M. (1996). Creativity in context: Update to "The social psychology of creativity."Boulder, CO: Westview Press.

Arnheim, R. (1962). The genesis of a painting: Picasso's Guernica. Berkeley, CA: Univ. of California Press.

Bandelj, N. (2003). How method actors create character roles. Sociological forum, 18, 387-416.

Berliner, P. (1997). Give and take: The collective conversation of jazz performance. In R.K. Sawyer. (Ed.) Creativity in performance. (pp. 9-41). Greenwich, CT: Ablex. 
Bruner, J. S. (1973). Organization of early skilled action. Child development, 44, 1-11. doi: $10.2307 / 1127671$

Csikszentmihalyi, M. (1997). Creativity: Flow and the psychology of discovery and invention. New York, NY: HarperCollins.

Diderot, D. (1957). The paradox of the actor. New York: Hill\& Wang. (Original work published 1770).

Doyle, C. L. (2011). Dimensions of the creative episode: Old categories, new perspectives. Creativity research journal, 23, 51-19. doi: 10.1080/10400419.2011.545748

Doyle, C. (2013). The multiple realities of the actor in rehearsal. Proceedings of the international symposium on performance science, 4, 47-52.

Doyle, C. L. (2016). Multiple realities: The changing life worlds of actors. Journal of phenomenological psychology, 47, 107-133.

Fox (2006). Inside out versus outside in. Retrieved from http://an-actorrepairs.blogspot.com/2006/12/inside-out-vs-outside-in.html

Glăveanu, V. (2010). Paradigms in the study of creativity: Introducing the perspective of cultural creativity. New ideas in psychology, 28, 79-93.

Glăveanu, V, Lubart, T., Bonnardel, N., Botella, M. , de Biaisi, P., Desainte-Catherine, M., Georgsdottir, A., Guillou, K., Kurtag, G., Mouchiroud, C., Storme, M., Wojtczuk, A. \& Zenasni, F. (2013). Creativity as action: Findings from five creative domains (Retrieved from the Frontiers in psychology website: http://journal.frontiersin.org/ article/10.3389/fpsyg.2013.00176/fulli: 10.3389/fpsyg.2013.00176) doi: 10.3389/fpsyg.2013.00176

Hassin, R. R., Bargh, J. A., \& Zimerman, S. (2009). Automatic and flexible: The case of nonconscious goal pursuit. Social cognition, 27, 20-36. doi: 10.1521/soco.2009.27.1.20

Moore, S. (1984). The Stanislavski system. New York: Penguin.

Nemiro, J. (1997). Interpretive artists: A qualitative exploration of the creative process of actors. Creativity research journal, 10, 229-239. doi: 10.1207/s15326934crj1002\&3_12

Noice, H., \& Noice, T. (2006). What studies of actors and acting can tell us about memory and cognitive functioning. Current Directions in Psychological Science, 15, 14-18. doi: 10.1111/j.0963-7214.2006.00398.x

Noice, T., \& Noice, H. (1997). The nature of expertise in professional acting: A cognitive view. Mahwah, NJ: Erlbaum.

Noice, T., \& Noice, H. (2002). The expertise of professional actors: A review of recent research. High ability studies, 13, 7-19.

Olivier, L. (1986). On acting. New York: Simon and Schuster. 
Oatley, K. (2002). Emotions and the story worlds of fiction. In M. C. Green, J. J. Strange, \& T. C. Brock, (Eds). Narrative impact: Social and cognitive foundations. (pp. 39-69) Mahwah, NJ, US: Lawrence Erlbaum Associates.

Piaget, J. (1952). The origins of intelligence in children. M. Cook (Trans.) New York: Norton.

Sawyer, R. K. (1997). Improvisational theater: An ethnotheory of conversational practice. In R.K. Sawyer. (Ed.) Creativity in performance. (pp. 171-193). Greenwich, CT: Ablex.

Sawyer, R. K. (2010). Individual and group creativity. In J. Kaufman and R. Sternberg (Eds). The Cambridge Handbook of Creativity. (pp. 366-380). New York, NY, US: Cambridge University Press.

Schütz, A. (1945). On multiple realities. Philosophy and phenomenological research, 5, 533-576.

Schütz, A. (1951). Making music together: A study in social relationship. Social research, 18, 76-97.

Stanislavski, C. (1986). An actor prepares. (Trans.). London: Methuen. (Original work published in 1936).

Strasberg, L., \& Morphos, E. (1987). A dream of passion: The development of The Method. Boston: Little, Brown.

Corresponding author at: Charlotte L. Doyle, Psychology Department, Sarah Lawrence College, 1 Mead Way, Bronxville, NY, 10708, USA.

E-mail: cdoyle@slc.edu 